once from M. Danne's results that the period of radiouranium must be long compared with that of uranium X. Thus M. Danne's discovery neither assists nor makes it more difficult to explain the results recorded in this letter. It is obvious that we have here really a very complex series of changes not capable of immediate interpretation.

FREDERICK SODDY.

\section{Are the Senses ever Vicarious?}

Ir is a prevalent opinion that if a human being is bereft of one sense, one or more of the other senses become more acute, and thus establish a compensation. For example, it is generally believed that the blind have the senses of touch and of hearing, more especially of touch, developed to a degree of acuteness not found in those who see, and that, in this way, the blind find their way about the world with an accuracy that is often surprising. The blind have even been credited with the ability to discriminate colours by the sense of touch, and some have attempted to support this supposition by an appeal to the sense of heat or cold possibly, for physical reasons, associated with a particular colour. A compensating arrangement has also been attributed to the deaf, and more especially to the deaf-blind. Such notions, however, must be abandoned before the evidence of recent investigations.

The question is discussed with much shrewdness in a paper on the physiology of the blind, by M. Kunz, director of the Institution for the Blind at Illzach-Mülhausen. $\mathrm{He}$ refers especially to the observations of Prof. Griesbach, made on a considerable number of blind persons in the Mulhausen Institution, and also, for the sake of comparison, on pupils in the public schools of Mülhausen of the same age. The results are somewhat surprising. As regards perception of the direction of sound, there is no difference between the seeing and the blind. The average distance at which sounds could be heard was essentially the same in both classes. As tested by Zwaardemaker's olfactometer, the delicacy of the sense of smell was rather in favour of the seeing. Griesbach used his own æsthesiometer, with parallel pins on springs, instead of the old Weberian method with compasses, in testing the acuteness of touch, with the result that the average minimum distance, say on the tip of the forefinger, \&e., at which two points were felt was greater in the blind than in the seeing; in other words, that the seeing had a finer sense of touch than the blind. It is generally supposed that the palp of the forefinger of the right hand, which is used by the blind in feeling the points in Braille's system of teaching the blind to read, must be very sensitive, but this was found not to be the case. Too high a degree of sensitiveness to touch is rather unfavourable to discriminating the points in Braille's type, and it is curious that when, in the blind, the epidermis of the skin covering the right forefinger becomes thickened by manual labour or by laborious practice in "reading," the discrimination of the points becomes easier. It was observed, also, that sometimes in the blind there was a difference as regards receiving impressions between the two forefingers.

There appears to be no evidence, iherefore, that blindness, per se, increases the sensitiveness of the other senses, but, on the principle that if one sense is defective the others are likely to be also defective, the other senses, in the average blind, are less acute than in the seeing. How, then, are we to explain the wonderful way in which the blind avoid obstacles and find their way about? It has been supposed that by practice the skin of the face, in particular, becomes more sensitive, or, in other words, that the blind habitually pay attention to currents of air playing on their faces, and especially they may be influenced by sensations of temperature. They say that they "know" they are near a wall because they "feel" it, although they do not touch it. It would be interesting to examine the blind as regards the sensitiveness of the hot and cold spots of the skin revealed by Goldscheider and others. The theory of sensitiveness to the direction and temperature of air currents is supported by the observation that the blind do not so readily avoid an obstacle if the face is covered or even if they are blindfolded. This suggests the question: Are all so-called blind people absolutely insensitive to light?

It is also believed that the blind pay an almost involuntary attention to the direction and quality of sounds. The blind man "taps" his stick. When snow is on the ground the blind have difficulty in avoiding obstacles. One must not forget, however, the psychical element that enters into the question. The effort of attention is superadded to the sensory impression. Impressions may reach the sensorium of which we are usually unconscious, but they may be detected by an effort of attention. This was strongly pointed out by Helmholtz. The senses of the blind are not more acute than those of normal people, but the necessities of the case oblige the blind to pay attention to them. JOHN G. MCKENDRICK.

\section{The Zoological Position of Tarsius.}

Two years ago (Nature, May 2, 1907, pp. 7 and 8) I directed attention to the fact that the recent additions to our knowledge of the Primates would compel us to look upon this order as being composed of three diversely specialised phyla of subordinal rank. It seemed clear that we should have to adopt some such subdivision of the Primates as that employed by Gadow (" A Classification of Vertebrata," London, I898, pp. $5^{2}$ and 53 ), who called the three suborders Lemures, Tarsii, and Simiæ respectively.

The researches of Hubrecht had shown that in respect of certain phases in its developmental history Tarsius differs from the lemurs and resembles the apes, and, as the result of the examination of its brain, I had come to the conclusion that Tarsius is much more primitive, and at the same time distinctly more pithecoid, than the lemurs (Linnean Society's Journal, r903). But Hubrecht would interpret these facts (see NATURe, December 24, I908, p. 229) as a demand for the exclusion of the lemurs from the Primates. The memoirs published within recent years by Forsyth Major, Earle, Standing, and the writer have made it perfectly clear that the demonstration of the affinities of Tarsius to the apes does not in any way affect the recognition of the fact that it is at least as nearly related to the lemurs, so that Hubrecht's proposal to restrict the term Primates to Tarsius and the apes lacks any adequate justification.

At the last meeting of the British Association I pointed out that the results of stimulation of the brain in lemurs and the examination of the distribution of the histologically distinct cortical areas by Page May, Wilson, and myself had revealed a close resemblance to the condition found in the apes. In opposition to the views of Vogt, Brodmann, Halliburton, and Mott, we found that a true sulcus of Rolando-which is peculiarly distinctive of the Primates - showed a tendency to develop in every prosimian family, and that in the lemur Perodicticus the morphology of the cerebral hemisphere is identical in almost every respect with that of the American monkey Pithecia. These facts bear unmistakable witness to the right of the lemurs to be included in the Primates.

In a monograph on the human hair by Friedenthal, a curious distinctive feature of the distribution of the hair in the Simiæ is mentioned. This author states that in man and all the other Primates (among which he does not include the lemurs) the sole of the foot is absolutely devoid of hair, not only in the adult, but also in the fœtus, and the line of demarcation between the hairless and the hairy skin runs across the back of the heel; but in the Prosimia the posterior part of the sole of the foot is coated with hair. I have examined a series of specimens of Tarsius given to me by Dr. Charles Hose, and find that in the manner of distribution of the hair on the foot Tarsius differs from the apes and agrees with the lemurs. At a time when so much weight is being attributed to facts of relatively slight significance on the other side, it seems worth pointing to this curious straw of evidence, which shows that, as the Primate stream flowed from its source among a group of Tarsius-like mammals, the apes and the lemurs were merely divergent branches of this stream, and that the latter suborder, although definitely specialised in structure, remained nearer to the Tarsii than the apes.

Cairo, February i 7 . 